In view of the large excess of potassium iodide employed in the iodide method, it is probable that the iodate method is cheaper.

The potassium iodate solution is perfectly stable and can be preserved without change for years, if protected from evaporation. Ordinarily it is unnecessary to standardize the solution, except by weighing out a known amount of the salt and dissolving it in a known volume. However, should there be any uncertainty in regard to the purity of the salt, or in connection with the relations of the volumetric apparatus, it would be advisable to standardize with pure copper, putting it through all the operations of the process, and thus eliminating also any slight constant errors.

With the precaution just mentioned, the process is capable of reaching a very high degree of refinement, for the method of titration is one of the sharpest and most uniform in its results. Since most of the iodine goes into the small volume of chloroform, the accuracy of the end-reaction is extraordinary.

SHEFFIELD LABORATORY,

NeW HAVEN, CONN.

\title{
SODIUM PEROXIDE IN CERTAIN QUANTITATIVE PROCESSES.
}

BY S. W. PARR.

Received February 21, 1908.

Sodium peroxide as a reagent in qualitative analysis, described by the writer ${ }^{1}$ has been found, after a number of years of actual service, to have advantages which entitle it to a far wider recognition and a more detailed study for that particular purpose. The same article states "that other properties have developed, mainly of interest in quantitative methods, which it is hoped will be of sufficient value to warrant further notice." It is in connection with this latter phase of the subject that the following processes are offered.

The adaptations of sodium peroxide here referred to are largely the outgrowth of the writer's experience in the use of that substance as a combustion medium for calorimetric determinations. This material has been recognized for some time as a good fusion reagent where both solution and oxidation are to be effected, but the usual methods of fusion in an open vessel are characterized by too great violence and danger of loss as well as by serious decomposition of the containing vessel. By carrying on the fusion in a closed vessel, it is possible to so adjust reagents as to bring about a quiet fusion without spurting. Owing to the concentration of the very great heat within the mass, the walls of the containing vessel must be kept relatively cool by submerging the same in water, thus preventing the corrosion of the container while at the same time there is no interference with the chemical reaction. An idea of

1 This JOURnal, I9, 34 I. 
the intensity of the heat in the interior of the mass may be gained from the experience occasionally met with of having soft iron wire melted into a round shot. Experiments have been carried on to determine the best conditions for securing a quiet fusion upon substances of widely varying character. In this work a closed cartridge only has been employed. Experiments have been made with bombs of various sizes and of various compositions. A bomb was made of 30 per cent. nickel steel but no special advantage was observed in its use. A bomb of about five times the usual capacity, was also made of the same material but the increase in the charge which this permitted resulted in the development of too great a quantity of heat to warrant its general adoption. In case the walls are melted through, the contact of the molten mass with the surrounding water produces a disturbance with more or less of the characteristics of an explosion. Pringsheim ${ }^{1}$ has adapted the method to the determination of the halogens in organic compounds and described a special form of closed crucible for carrying out the process. It is the purpose of this article to make record of a still wider use of the method and to call attention to the adaptability of the bomb which accompanies the Parr calorimeter. It may not have any great advantage over the closed crucible of Pringsheim, but the fact that the bomb is not infrequently already at hand may be a reason for calling attention to it.

Fig: I illustrates the bomb in its present form. The ignition is brought about by dropping into the stem a short slug of soft iron or pure nickel wire heated to redness. It will lodge at the valve $\mathrm{M}$, when, by pressing down quickly with the forceps at $\mathrm{O}$, the hot wire is released and drops into the mixture. From the construction of the cartridge it may be seen that, when submerged, the holes in the screw caps provide for the circulation of water about the two ends of the cylinder, thereby permitting the use of rubber gaskets. An air space about the lower part of the cylinder as at $\mathrm{E}$ provides for a less rapid cooling of the walls of the chamber than would be the case if the cylinder at that part were in direct contact with the water. The ends of the cylinder are removable and the fused mass is driven ut with a short rod provided for the purpose. A jet of hot water readily washes out the interior surfaces and the entire fusion

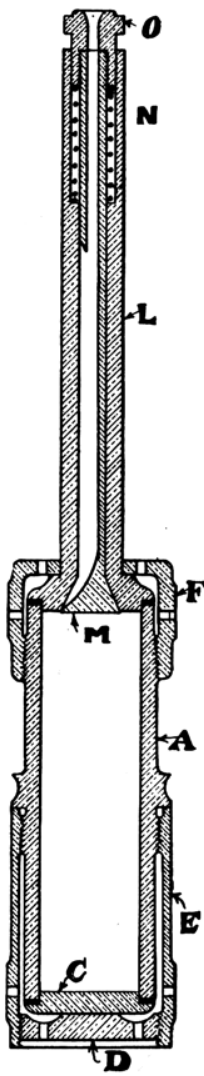

Fig. I. is thus brought into solution with a minimum amount of water, 50 or 75 cc. being ample.

${ }^{1}$ Am. Chem. J., 31, 386. 
In applying the process to inorganic substances it is necessary to have a mixture which will carry on the combustion independently of the material under examination. It is also true that many organic substances require, for complete combustion, conditions not provided by sodium peroxide alone. ${ }^{1}$ Thus, with carbon and hydrogen, the conditions for the reactions are indicated separately by the following equations:

$$
\begin{aligned}
& 2 \mathrm{Na}_{2} \mathrm{O}_{2}+\mathrm{C}=\mathrm{Na}_{2} \mathrm{CO}_{3}+\mathrm{Na}_{2} \mathrm{O} \\
& \mathrm{Na}_{2} \mathrm{O}_{2}+\mathrm{Na}_{2} \mathrm{O}+\mathrm{O}+{ }_{4} \mathrm{H}={ }_{4} \mathrm{NaOH}
\end{aligned}
$$

A series of tests for determining the most suitable reagents has resulted in the following mixture, applicable also to inorganic as well as organic substances. For a detailed statement of the action of these reagents, reference should be made to a recent article on "Calorimeter Constants."

StTandard Fuston Mixtire No. 1.

so grams (I measure) of sudium peroxide,

0.5 " potassium chlorate,

0.5 " benzoic acid.

A thorough mixing is effected by enclosing the charge in the bomb and shaking; the bomb is then submerged to prevent the melting through of the metal and the red hot slug is dropped through the stem as above indicated. The process is complete in two or three minutes, when the cartridge may be opened and the fusion transferred to a beaker, where the dissolving and boiling out of the oxygen is accomplished in about five minutes more. These are the fundamental conditions for a large class of substances, some of which are detailed as follows:

Sulphur and Arsenic in Pyritic Ores of Iron and Copper.--If to the charge as just described we add 0.25 gram of a pyritic ore, we shall have a complete decomposition of the pyrites along with the combustion, so that within a very few minutes after the weighing and mixing in the cartridge (fifteen minutes at the most, and usually within ten minutes if desired), we may have our sulphur as sulphate in solution ready for precipitation with barium cliloride. Nor is accuracy sacrificed to speed, for the total absence of contamination from the sulphur of gas flames is avoided. Moreover, as Hillebrand has shown, ${ }^{3}$ with the bulk of the solution measuring $200 \mathrm{cc}$. to $300 \mathrm{cc}$. dehydration for the removal of silica is unnecessary. This method, therefore, is especially well adapted to the determination of sulphur in mineral substances, and is greatly to be preferred to the usual Fresenius method. For pyrites, moreover, it has decided advantage over the Ininge procedure. 'This is especially true in the case of roasts containing small amounts of sulphur and with pyrites containing copper. In all these cases a perfect fusion is sectred. Upon

I This JOURNal, 29, I6IG.

2 Ibid., 29, I6I8.

Bulletin 305, U. S. Geol. Surv., p. 160. 
boiling, the ferrate is decomposed, precipitating the iron, but a clear solution results upon acidifying. If it is desired to precipitate the copper, it is necessary to make slightly acid and then faintly alkaline with sodium carbonate, since the copper hydroxide is soluble in an excess of alkali. Arsenic, if present, is in the fusion as sodium arsenate and may be determined by any of the accepted methods. In the following tests a pyritic ore with approximately ro per cent. of copper was used. The arsenic was determined for comparison by the distillation method. ${ }^{1}$ A parallel fusion was also made, using a known quantity of pure arsenic trioxide and copper oxide.

TABle I.-Determination of Sulphur in Ores by Fusion with Sodium Peroxide.

\begin{tabular}{|c|c|c|}
\hline Material. & Fusion with $\mathrm{Na}_{2} \mathrm{O}_{2}$. & Lunge's method. \\
\hline Galena. & 14.59 & 13.83 \\
\hline Zinc blende. & . 29.28 & 28.73 \\
\hline Arsenical py & $\ldots 29 \cdot 32$ & 28.52 \\
\hline
\end{tabular}

Table II.-Determination of Arsenic by Fusion with Sodium Peroxide

\begin{tabular}{|c|c|c|c|}
\hline Material. & $\begin{array}{l}\text { A rsenic found } \\
\text { volumetrically cal- } \\
\text { culated to } \mathrm{As}_{2} \mathrm{O}_{3} \text {. }\end{array}$ & $\begin{array}{l}\text { Arsenic found } \\
\text { gravimetrically } \\
\text { as } \mathrm{As}_{2} \mathrm{O}_{3} \text { and cal- } \\
\text { culated to } \mathrm{As}_{2} \mathrm{O}_{3} \text {. }\end{array}$ & $\begin{array}{l}\text { Arsenic } \\
\text { present } \\
\text { as } \mathrm{As}_{2} \mathrm{O}_{3} \text {. }\end{array}$ \\
\hline $\mathrm{As}_{2} \mathrm{O}_{2}+\mathrm{CuO} \ldots \ldots \ldots \ldots$ & $100 \cdot 3$ & $\ldots$ & 100.0 \\
\hline $\mathrm{As}_{2} \mathrm{O}_{3}+\mathrm{CuO} \ldots$ & $\cdots$ & 99.97 & 100.0 \\
\hline Arsenical ore with iron an & $1 \mathrm{~d}\{(a)$ I I 42 & $\cdots$ & 11.37 \\
\hline$\ldots \ldots \ldots \ldots$ & $\ldots l(b) 11.68$ & $\cdots$ & 11.43 \\
\hline
\end{tabular}

Sulphur in Coal, Coke, Ashes, Etc.-In the case of coal and coke, the method has very decided advantages over the usual Eschka process. With coal and coke, one-half gram of these substances should be taken and the benzoic acid omitted from the fusion mixture. In ashes, however, the fusion is affected by the use of the benzoic acid, as above described. If desired, the fusion will easily allow the use of from one-half to one gram of ash material. For sulphur in coal and coke, Sundstrom ${ }^{2}$ has described a special crucible based on the reaction with sodium peroxide, as suggested by the use of that material for calorimetric purposes. Von Konek ${ }^{3}$ makes direct use of the bomb as provided for calorimetric determinations. Both of these writers, with still others, give comparative data showing the satisfactory nature of the results. By use of the fusion mixture, as above given, a much wider range of substances is covered, including those with little or no ability to carry on the combustion by themselves.

By reference to Table I, it will be seen that the results for sul.phur in mineral matter are slightly lower by the Lunge method. Thins is a natural result of the methods employed, since the fusion process gives

1 Z. anal. Chem., 21, 266.

2 ThIS JOURNAL, 25, I 84 .

${ }^{3} Z$. angev. Chem., I903, $5 \mathrm{I} 6$. 
the total sulphur, including any sulphates present. In case of high iron, it is, of course, removed by filtration before precipitating the sulphur.

Sulphur in Rubbor.-Rubber may be completely oxidized if brought to a reasonably fine state of division. This may readily be accomplished by grating the rubber on a new file, though the purer grades may be better cut into snall pieces with a sharp knife. One- or two-tenths of a gram with the standard charge will give a perfect combustion. 'The precipitation of sulphur as a sulphate is carried on in the usual manner.

T.MBLE III.-STLIHH IN RUBber.

\begin{tabular}{|c|c|c|c|c|}
\hline Material. & $\begin{array}{l}\text { Amount } \\
\text { taken. } \\
\text { Gram. }\end{array}$ & Method. & $\begin{array}{l}\text { Sulphur from } \\
\text { peroxide } \\
\text { method. } \\
\text { Per cent. }\end{array}$ & $\begin{array}{c}\text { Eschka's } \\
\text { method }\end{array}$ \\
\hline "Ebonite" rubber packing. & $.11 \cdot 1$ & $\begin{array}{c}\text { 10.0 g. peroxide } \\
0.5 \mathrm{~g} \text {. chlorate } \\
0.3 \mathrm{~g} \text {. benzoic } \\
\text { acid }\end{array}$ & (b) 4.30 & $4 \cdot 32$ \\
\hline White soft rubber tubing. & $0 . \mathrm{I}$ & same & $\begin{cases}(a) & 0.98 \\
(b) & 0.92\end{cases}$ & \\
\hline
\end{tabular}

Halogens, Sulphur, Iitc, in Oroanic Compounds.-As a substitute for the Carius method for decomposing organic compounds of the halogens, the nethod is in every way to be preferred. It is applicable also to organic compounds of sulphur, phosphorus, arsenic, etc. Pringsheim ${ }^{1}$ also refers to this use of sodium peroxide as a qualitative reagent and gives details for carrying out the combustion process. Our own experience proves that, with organic compounds a simple modification of the standard charge is sufficient in that the sum of the material under examination plus the benzoic acid should equal the usual amount of combustible, viz., 0.5 gram. That is, if 0.2 gram of an organic substance such as aniline hydrochloride is taken, the amount of benzoic acid should be 0.3 gram. However, these quantities are flexible within certain limits, though the total amount of organic combustible should not greatly exceed 0.5 or 0.6 gram.

Since, with the halogents, it is necessary to avoid the use of chlorine compounds, the fusion reagents, potassium chlorate and benzoic acid, above given, may be replaced by a mixture made up as follows:

Bono Magnesium Mixtuke.

Parts.

Boric acid in fine powder. . . . . . . . . . . . 5

Potassiun nitrate, powdered ..............

Magnesium, powdered. .

The amount of the above boronitrate-magnesium mixture may be increascd from 0.5 to 2 grams or until a satisfactory combustion is secured by means of the increased quantity of metallic magnesium present. The charge, therefore, for this class of compounds would be:

1 Am. Chom. I., 31, 350; lior., 37, 2155. 
Fusion Mixture No. 2.

Io grams (I measure), sodium peroxide,

I to 2 grams boro-magnesium mixture,

0.3 to 0.5 gram carbon compound.

In the case of organic substances that are liquid at ordinary temperatures, the conditions are not altered except with very volatile substances where an exact weight is difficult to obtain. For such material a very light bulb of glass is blown from thin-walled tubing of about two or three $\mathrm{mm}$. caliber. This is fused off with a capillary stem and weighed. With care, it is not difficult to make bulbs of one-half inch or more in diameter, weighing less than 0.2 gram. When so made, they may be easily broken after the charge is made up and the cartridge closed. About 0.2 or 0.3 gram of liquid is drawn into the bulb and the capillary placed in the cartridge directly upon the bottom and the standard charge with No. I or No. 2 placed above it. After closing the cartridge, a sharp rap on a solid desk will break the glass, when, by shaking, a thorough mixture is secured. This procedure has given good results with benzene and similarly volatile materials.

TABle IV.-Chlorine by Fusion with Sodium Peroxide.

Material.

Sodium chloride........ Fusion mixture No. 2

Aniline chloride......... Fusion mixture No. 2
Found as AgCl. Theoretical.

60.48

60.60

27.63

$27 \cdot 36$

Carborundum.-Finely divided carborundum bums readily by use of fusion charge No. 2. The carbon in this fusion may be determined volumetrically. In a separate sample, however, the metallic iron should be determined by extracting the same with a magnet and the free silica may be determined by volatilizing with hydrochloric acid, since the silicon of the carbide is not attacked by that reagent. The total silicon from the fusion should then be corrected to ascertain the amount in combination as $\mathrm{SiC}$.

\begin{tabular}{|c|c|c|}
\hline Constituents. & Method. & Per cent. \\
\hline $\mathrm{SiO}_{2}$ & Volatilized with $\mathrm{HF}$ & 8.27 \\
\hline Iron as $\mathrm{Fe}$. . & Removed by magnet & $4 \cdot 37$ \\
\hline Silicon as Si & Fusion mixture No. 2 & $63 \cdot 5^{8}$ \\
\hline Carbon as $\mathrm{C}$ & Volumetric from fusion mixture No. 2 & 23.67 \\
\hline
\end{tabular}

While various other substances have been tested with satisfactory results such as shales, fire clays, titanium, ores, etc., it is thought that the above descriptions cover a sufficiently wide range of material to indicate the uses to which the method may be put.

I am indebted for analytical results to six or eight senior and graduate students of this department who have from time to time worked with 
the methods as indicated. Special acknowledgment should be made to Mr. F. W. Gill for results on arsenic, chlorine and carborundum. UNIVERSITY OF ILLINOIS,

URBANA, ILL.

\title{
THE COMPARATIVE OXIDIZING POWER OF SODIUM PEROXIDE AND ITS USE IN QUALITATIVE ANALYSIS.
}

\author{
By D. F. CALEANE.
}

Received February $12,1908$.

The detection of chromium in qualitative analysis rests on its oxidation to the chromate and the precipitation of chromate of lead in acetic acid solution. The oxidation is usually effected by chlorate of potash on the solution of chromium hydroxide in strong nitric acid. If by any chance the nitric acid chosen is not strong enough or has become diluted, the oxidation will not occur and the test fails. It is necessary for success that the hyclroxides possibly containing iron, aluminium and chromium be freed of water as much as it is possible by drying them quickly by heating. In this part of the procedure the student usually fails to work properly, not enough water is removed, and the subsequent oxidation does not occur. As I have found, in teaching classes in this subject, so much trouble in getting the student to properly observe precautions, it seemed of advantage to apply a test which would be effective and not so much dependent on a certain set of conditions.

Some experiments were accordingly made on the action of certain other oxidizing agents. Among these were chosen sodium peroxide and bromine water. The preference was for the former, as it is to be obtained in a convenient solid form, and possesses few of the disagreeable features of bromine water. A o.I $N$ solution of chrome alum was prepared, each cubic centimeter holding $0.0332 \mathrm{~g}$. of chrome alum, answering to $0.005 \mathrm{~g}$. of $\mathrm{Cr}_{2} \mathrm{O}_{3}$. Next, the oxidation of portions of this solution with peroxide of sodium and bromine water was carried out to see what the comparative efficacy of these two reagents is on solutions containing known amounts of chromium. In this connection an interesting feature in the action of soditn peroxide on chromium solutions was met with, that at first led to the belief that bromine water was more efficient. The dilutions were carried to the point where the amount of chromic oxide present was only $0.000125 \mathrm{~g}$., corresponding to $0.000085 \mathrm{~g}$. of chromium. At this extreme dilution, a safe test was secured with bromine water, but the sodium peroxide apparently failed at a concentration answering to $0.00025 \mathrm{~g}$. chromic oxide. The bromine water appeared to act equally well both hot and cold at all the different concentrations from $0.005 \mathrm{~g}$. chromic oxide down to $0.000 \mathrm{r} 25 \mathrm{~g}$. With the sodium peroxide there was no test with the presence of $0.005 \mathrm{~g}$. 